\title{
Keniscayaan Memahami Fikih Muamalat bagi Wirausaha
}

\author{
Zuhrinal M Nawawi \\ Universitas Islam Negeri Sumatera Utara \\ Jl. William Iskandar Ps. V, Medan Estate, Kec. Percut Sei Tuan, Kabupaten Deli \\ Serdang, Sumatera Utara \\ Zuhrinal.nawawi@uinsu.ac.id
}

\begin{abstract}
Islam as a universal religion, teaches all aspects of the lives of its adherents such as matters of worship, morals, including procedures in everyday life which we often call muamalat. For Muslim entrepreneurs, it is a necessity to know and understand religious law in business, especially fiqh muamalah. So that they understand about business and entrepreneurship; and understand the concept of fiqh muamalah, its scope in contemporary business, and the rules of fiqh that are appropriate for contemporary business. Islam emphasizes the importance of developing and upholding an entrepreneurial culture in the life of every Muslim. A Muslim entrepreneur must have basic qualities that encourage him to be a creative and reliable person in running his business or carrying out activities at the company where he works.
\end{abstract}

Keywords: Fikih Muamalat, Entrepreneur, Business

\begin{abstract}
ABSTRAK
Islam sebagai agama universal, mengajarkan segala aspek kehidupan pemeluknya seperti masalah ibadah, akhlak, termasuk tata cara dalam kehidupan sehari-hari yang sering kita sebut muamalat. Bagi wirausahawan muslim menjadi sebuah keniscayaan untuk mengetahui dan memahami hukum agama dalam bisnis khususnya fikih muamalah. Agar mereka paham tentang bisnis dan kewirausahaan; dan mengerti konsep fikih muamalah, ruang lingkupnya dalam bisnis kontemporer, dan kaidah-kaidah fikih yang sesuai dengan bisnis kontemporer. Islam menekankan pentingnya perkembangan dan penegakan budaya kewirausahaan dalam kehidupan setiap muslim. Seorang wirausahawan muslim harus memiliki sifat-sifat dasar yang mendorongnya untuk menjadi pribadi yang kreatif dan andal dalam menjalankan usahanya atau menjalankan aktivitas pada perusahaan tempatnya bekerja.
\end{abstract}

Kata Kunci: Fikih Muamalat, Wirausaha, Bisnis 


\section{PENDAHULUAN}

Bisnis dizaman sekarang adalah kenyataan yang sangat membingungkan. Banyak variabel mempengaruhi dan memutuskan kegiatan bisnis. Rumitnya bisnis secara langsung diidentikkan dengan kerumitan budaya masa kini. Bisnis sebagai sebuah gerakan sosial dapat dilihat pada tiga perspektif yang unik, tetapi biasanya tidak mungkin untuk memisahkan mereka, khususnya perspektif moneter, perspektif moral, dan perspektif hukum.

Bisnis menurut perspektif moneter, adalah tindakan finansial. Kegiatannya dalam bentuk tukar menukar, jual beli, memproduksi, memasarkan, bekerja, mempekerjakan, dan interaksi manusiawi lainnya, yang sepenuhnya bertujuan untuk menghasilkan keuntungan. Saat ini keuntungan bisnis dikomunikasikan dalam bentuk uang tunai, tetapi itu bukan merupakan yang hakiki dalam bisnis. Yang penting adalah bahwa gerakan manusia ke manusia ini ditujukan untuk menghasilkan keuntungan dan itulah alasan mengapa tindakan moneter terjadi. Namun perlu digarisbawahi bahwa pencarian keuntungan dalam bisnis tidak dilakukan sendiri-sendiri, melainkan dilakukan secara gotong royong. Bisnis terjadi sebagai korespondensi sosial yang menguntungkan bagi kedua pemain yang disertakan. Dalam konsep Islam bisnis ini disebut juga muamalat, kata Muamalat berasal dari bahasa Arab yang secara etimologis sama dan memiliki arti yang sama dengan al-mufa'alah (saling mengerjakan). Kata ini menggambarkan suatu kegiatan yang dilakukan oleh seseorang dengan seseorang atau beberapa orang dalam memenuhi kebutuhannya masing-masing. Sedangkan Fikih Muamalat adalah terminologi yang diartikan sebagai hukum-hukum yang berkaitan dengan perbuatan hukum manusia dalam urusan duniawi. (DR. SRI SUDIARTI, 2013).

Fikih Muamalat adalah pengetahuan tentang kegiatan atau transaksi berdasarkan hukum syariah, tentang perilaku manusia dalam hidup yang diperoleh dari argumen Islam secara rinci. Jenis-jenis muamalat dibagi menjadi dua, yaitu; Jenis muamalat yang hukumnya langsung ditunjuk oleh nash dengan memberikan batasan-batasan tertentu. Diantara permasalahan tersebut adalah masalah warisan dan larangan riba. Hukum semacam itu bersifat permanen dan tidak dapat diubah dan tidak menerima perubahan; Jenis muamalat yang tidak ditunjuk langsung oleh Nash, melainkan diserahkan kepada hasil ijtihad para ulama, sesuai dengan kreasi para ahli guna memenuhi kebutuhan umat manusia sepanjang waktu dan tempat, serta sesuai dengan situasi dan kondisi masyarakat itu sendiri. Contohnya adalah Bai' al-Mu'athah (jual beli dengan saling menyerahkan uang dan mengambil barang tanpa disertai ijab dan qabul) (DR. SRI SUDIARTI, 2013). 
Selain mengakui peran sentral dari sudut pandang ekonomi dalam bisnis, perlu juga memperhatikan sudut pandang lain yang tidak boleh diabaikan, yaitu sudut pandang etika atau moralitas. Artinya, untuk menjaga produktivitas agar bisa meraih keuntungan yang besar, bolehkah melakukan dengan segala cara? Mengejar keuntungan adalah hal yang wajar, asalkan tidak diraih dengan mengorbankan orang lain. Banyak kasus terjadi, karena obsesi mengejar keuntungan besar, kerusakan lingkungan terjadi dimana-mana. Jadi, harus ada batasan dalam mewujudkan tujuan perusahaan. Tidak semua hal dapat dilakukan dalam kegiatan ekonomi untuk mendapatkan keuntungan. Dalam setiap aktivitas selalu ada kendala etika bagi perilaku kita, termasuk perilaku ekonomi. Jadi, bisnis yang baik bukan hanya bisnis yang menguntungkan. Bisnis yang baik juga bisnis yang baik secara moral. dan bisnis yang sesuai dengan syariat Islam kita kenal dengan sebutan bisnis syariah. Bisnis syariah mengandung nilai tauhid yang mencakup; misi khilafah/istikhlaf; misi ibadah; keseimbangan antara dunia dan akhirat. Selain itu, dalam berbisnis syariah juga menuntut agar para pelaku bisnis selalu memiliki akhlak yang baik dalam setiap perilaku dan ucapannya. Akhlak yang baik yang dimaksud adalah: Kejujuran, Keterbukaan, Kasih Sayang, Solidaritas, Kesetaraan, Tanggung Jawab, Profesionalisme, dan Konstituen. (Anshori et al., 2009).

Sisi hukumnya, tidak dapat dipungkiri bahwa bisnis juga terikat oleh hukum. "Hukum Niaga" atau "Hukum Bisnis" adalah cabang penting dari hukum modern. Dalam praktik bisnis, banyak masalah yang muncul dalam kaitannya dengan hukum, baik di tingkat nasional maupun internasional. Seperti halnya etika, hukum adalah sudut pandang normatif, karena mengatur apa yang harus dilakukan atau tidak dilakukan. Dari segi norma, hukum bahkan lebih jelas dan pasti daripada etika, karena peraturan hukum ditulis hitam putih dan ada sanksi tertentu, jika ada pelanggaran. (Abdullah et al., 2018). Dan bisnis yang sesuai dengan landasan Al-Qur'an dan Al-Hadist kita kenal dengan bisnis syariah. Hukum Bisnis Syariah harus memenuhi karakteristik sebagai berikut; Hukum asal muamalah adalah diperbolehkan; Tujuannya adalah untuk kemaslahatan umat manusia; Hukum muamalah terdiri dari hukum yang tetap dan hukum yang berubah; Objeknya harus halal dan tayyib; Tidak mengandung Gharar.

Islam sebagai agama universal, mengajarkan segala aspek kehidupan pemeluknya seperti masalah ibadah, akhlak, termasuk tata cara dalam kehidupan sehari-hari yang sering kita sebut muamalat. Namun sebagai salah satu aspek terpenting dalam kehidupan umat Islam, ketentuannya tidak disebutkan secara rinci dan jelas dalam Al-Qur'an sehingga diperlukan penjelasan yang lebih rinci dan mendalam melalui ijtihad para ulama. 
Melihat fenomena seperti ini, pada masa perkembangan peradaban Islam, para ilmuwan dan pemikir Muslim mulai meneliti dan mencari penjelasan tentang masalah muamalat ini, baik melalui tafsir Al-Qur'an, hadits Nabi Muhammad maupun pendapat para sahabat yang hidup di zaman Nabi yang lebih tahu bagaimana cara Nabi bermuamalat yang mulai berkembang pada abad pertama Hijriyah. (DR. SRI SUDIARTI, 2013).

Seiring dengan perkembangan zaman, problematika dan fenomena muamalah semakin beragam sehingga membutuhkan kajian yang lebih mendalam. Untuk menjawab tantangan ini, para peneliti kontemporer lebih memilih untuk tidak duduk-duduk melihat berbagai macam fenomena yang tak terhindarkan. Mereka mencoba mengkaji ulang dan berupaya menemukan jawaban atas persoalan fenomena muamalah dengan menggabungkan teknik-teknik yang wajar dan lumrah dengan inovasi yang ada. Bagi seorang pebisnis atau wirausahawan muslim menjadi sebuah keniscayaan untuk mengetahui dan memahami hukum agama dalam bisnis khususnya fikih muamalah. Sebagaimana dijelaskan dari Umar bin al-Khattab radhiyallahu 'anhu:

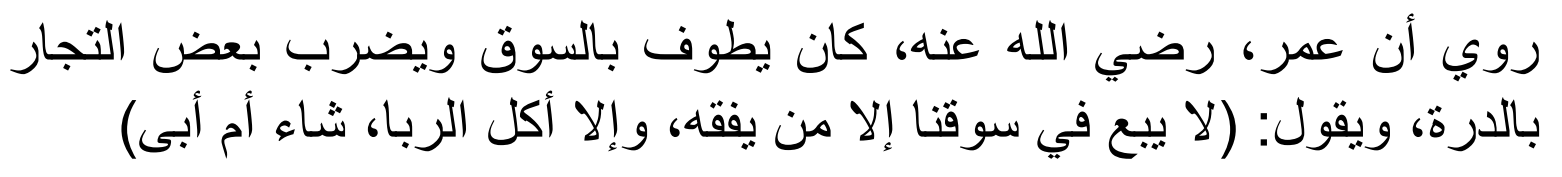

"Hanya orang-orang yang faqih (memahami ilmu agama) yang diperbolehkan berjualan di pasar kami, karena jika mereka tidak melakukannya, maka mereka akan memakan riba." (Sabiq, 1983)

Berdasarkan landasan pemikiran di atas, maka tulisan ini akan membahas tentang apa itu bisnis dan kewirausahaan? Lalu bagaimana sebenarnya konsep fikih muamalah itu, ruang lingkupnya dalam bisnis kontemporer, dan kaidah-kaidah fikih yang sesuai dengan bisnis kontemporer? Dan terakhir akan dikemukakan bagaimana seharusnya karakteristik seorang wirausaha?.

\section{METODE PENELITIAN}

Metode penelitian deskriptif kualitatif ialah riset yang digunakan untuk menguasai bagaimana orang memandang, menginterpretasikan dunia sosial-ekonominya dengan berhubungan secara langsung (Sugiono, 2017). Pendekatan pada riset ini memakai pendekatan kualitatif di mana menggambarkan sesuatu kondisi yang kompleks dari sudut pandang ilmiah untuk menganalisis kehidupan sosial masyarakat yang difokuskan pada kebiasaan dalam melaksanakan bisnis. Dari kondisi ini hendak diamati bagaimana mereka 
menyikapi perubahan-perubahan yang menyebabkan transformasi pola kebiasaan yang disebabkan oleh pergantian kondisi.

Sumber informasi yang digunakan ialah informasi sekunder, informasi diperoleh dari teori- teori serta bermacam data yang didapat secara tidak langsung dari bermacam sumber semacam buku, dokumen, website, berita tetang sikap bisnis wirausaha muslim serta pula informasi yang relevan dengan kebutuhan serta tujuan riset ini.

Langkah utama dalam riset ialah metode pengumpulan data dan informasi sebab bertujuan mendapatkan informasi standar yang sudah ditentukan. Pada riset kualitatif ini, pengumpulan informasi dicoba lebih banyak mefokuskan dari segi dokumentasi serta informasi relevan yang lain.

\section{HASIL DAN PEMBAHASAN}

\section{Bisnis dan Wirausaha}

Pemahaman hakiki bisnis adalah layanan melalui jual beli baik barang maupun jasa. Istilah ekonomi dan bisnis dilihat dari susunan kata yang terdiri dari kata ekonomi dan bisnis. Apa yang disiratkan oleh ekonomi adalah tentang bagaimana individu mengambil keputusan yang tepat, untuk menggunakan aset yang berguna (tanah, tenaga kerja, barang modal, perangkat keras, dan pengetahuan teknis) yang jumlahnya sedikit dan terbatas untuk menghasilkan berbagai produk yang berbeda, serta mendistribusikannya kepada berbagai anggota masyarakat agar mereka gunakan atau konsumsi. Jadi, bisa dikatakan bahwa ekonomi adalah fenomena masyarakat dalam memenuhi kebutuhannya untuk mencapai kemakmurannya. (Obisi \& Anyim, 2012)

Dalam bisnis, ada empat faktor yang menjadi pelaku bisnis utama; yaitu pemilik modal, pengelola, konsumen dan tenaga kerja. Pemilik modal adalah individu yang menempatkan uang tunai dalam bisnis tertentu dengan harapan mendapatkan keuntungan dari bisnis itu. Pengelola adalah orang yang menjalankan usaha dan bertanggung jawab kepada pemilik modal. Pengelola juga adalah seorang profesional yang memiliki daya saing untuk menghasilkan keuntungan, menumbuhkembangkan organisasi perusahaan, memperhatikan hidup perusahaan dan yang memiliki tanggung jawab.

Pemilik modal yang merangkap sebagai pengelola disebut wirausaha. Dia adalah orang yang dapat memanfaatkan peluang bisnis sebaik-baiknya; mempertimbangkan berbagai risiko dengan menangani bisnis dan mendapatkan bayaran uang tunai atau bentuk lain. Fokus perhatian para pebisnis terhadap konsumen saat ini tentu saja semakin besar 
karena persaingan bisnis yang semakin sengit dan anggapan bahwa pembeli adalah segalanya atau disebut raja dan harus dilayani dengan sebaik-baiknya. (Miller \& Collier, 2010)

Istilah wirausaha merupakan interpretasi dari kata entrepreneur. Kata tersebut berasal dari bahasa Perancis yang berarti "dapat diandalkan". Wajar, seorang wirausaha adalah orang yang bertanggung jawab untuk mengatur, mengawasi banyak risiko suatu usaha. Saat ini para entrepreneur melakukan banyak hal sehingga definisinya menjadi lebih luas. Wirausahawan adalah perintis yang dapat memanfaatkan dan mengubah celah menjadi pemikiran yang dapat dijual atau dipamerkan, memberikan nilai tambah dengan menggunakan upaya, waktu, pengeluaran, atau kemampuan mereka dengan niat penuh untuk menghasilkan keuntungan. Mereka adalah pembawa kemajuan dalam berbagai tantangan untuk mengejar pencapaian bisnis yang dimulai dengan cara yang teratur. Kekecewaan tidak dipandang sebagai akhir dari pertempuran, namun dianggap sebagai bahan investigasi yang harus dipusatkan untuk mencapai tujuan. (Acs, 2006)

Dalam bekerja, seorang pebisnis perlu memiliki rencana produk, teknik pemasaran, dan pengaturan dalam mengatasi masalah administratif yang kreatif untuk bersaing dengan organisasi yang lebih besar. Seorang wirausaha adalah seseorang yang menyatukan, mengawasi, dan menerima semua risiko ketika dia memulai bisnisnya untuk mendapatkan keuntungan.

Seorang pebisnis secara konsisten mengembangkan bisnisnya dengan menggunakan pemikiran barunya dalam mengenali item baru, strategi baru, menemukan desain bantuan baru dan masalah lain yang terkait dengan perputaran uang. Bisnis adalah kapasitas untuk berpikir dan merupakan aktivitas yang berguna dalam mengenali contohcontoh baru penciptaan dan administrasi.

Berikut ini adalah ungkapan Allah swt. diidentifikasi dengan contoh-contoh penalaran produktif, untuk lebih spesifik:

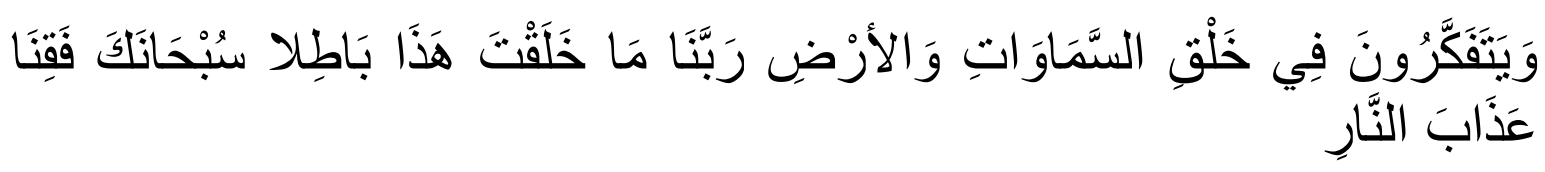

Artinya: “(yaitu) orang-orang yang mengingat Allah sambil berdiri atau duduk atau dalam keadaan berbaring dan mereka memikirkan tentang penciptaan langit dan bumi (seraya berkata): "Ya Tuhan Kami, Tiadalah Engkau menciptakan ini dengan sia-sia, Maha Suci Engkau, Maha peliharalak Kami dari siksa api neraka.” (Q.S. Ali-Imran: 191) 
Dalam ayat tersebut, kata berpikir (وَيَتَكَّرُونَ) dapat dikaitkan dengan contoh-contoh penalaran inventif sehubungan dengan peristiwa langit dan bumi dan setiap kemungkinannya. Para wirausaha seperti yang digambarkan di atas memiliki kualitas penalaran inventif dan imajinatif serta memiliki perilaku atau kegiatan yang bermanfaat dalam mengakui perubahan di bidang moneter dan kemajuan bisnis. (Al-Alak \& Eletter, 2010)

\section{Lingkup Muamalat Kontemporer}

Fenomena muamalat kontemporer belum dikenal di zaman klasik. Ekstensi ini mencakup setiap transaksi yang muncul pada zaman modern. Seperti uang kertas, saham, surat berharga, aset bersama, MLM (Multi Level Marketing), proteksi. Salah satu contoh lingkup ini adalah asuransi. Asuransi merupakan pertanggungan (perjanjian antara dua pihak; pihak yang satu berkewajiban membayar premi dan pihak yang lain berkewajiban memberikan jaminan sepenuhnya kepada pembayar premi, apabila terjadi sesuatu yang menimpa dirinya atau barang miliknya yang diasuransikan sesuai dengan perjanjian). Pada zaman klasik transaksi akad asuransi ini belum ada, walaupun akad ini dikiaskan dengan kisah dengan narasi mengikat unta sebelum meninggalkannya. Perjanjian ini dapat dianjurkan atau diperbolehkan dalam Syariah Islam selama tidak sesuai dengan apa yang dilarang dan memenuhi kualitas hukum bisnis syariah.

Transaksi Bisnis Kontemporer yang menggunakan nama lain meskipun substansinya cukup setua zaman tradisional, misalnya bunga bank yang benar-benar setara dengan riba, jual beli valuta asing. Walaupun riba telah berganti nama menjadi nama yang lebih baik yaitu bunga, namun pada dasarnya/substansinya tetap seperti semula dimana ada pihak-pihak yang menganiaya dan dianiaya, sehingga hukum bunga sama dengan riba yang jelas-jelas haram di Al-Qur'an.

Transaksi-transaksi masa kini yang menggunakan berbagai akad, misalnya IMBT (Ijarah Muntahiya bit Tamlik), MMQ (Musyarakah Mutanaqishah). Dalam lingkup ini membahas bahwa pada masa Kontemporer ini ada beberapa akad yang dimodifikasikan dalam suatu transaksi bisnis. Hal ini dapat dibenarkan atau diperbolehkan selama tidak sejalan dengan apa yang diharamkan dan memenuhi ciri-ciri hukum bisnis syari'ah. (DR. SRI SUDIARTI, 2013)

Beberapa penyesuaian terhadap akad klasik yang terjadi pada masa kontemporer antara lain; Hak Intifa' (menggunakan), misalnya wadhi'ah yad dhamanah; Biaya administrasi, misalnya dalam barang Qardhul Hasan; Ujrah (fee), misalnya dalam transaksi letter of credit (L/C), Transfer; Kredit, misalnya pada jual beli Murabahah; 
Perubahan sifat akad, contohnya wadiah (awalnya bersifat tidak mengikat menjadi mengikat); Janji (wa'ad), misalnya dalam transaksi Ijarah Muntahiya bi Tamlik; Wakalah

\section{Kaidah Fiqih Muamalat Kontemporer}

Kaidah fikih yang dapat dimanfaatkan dan untuk dipahami oleh seorang wirausaha mencakup hal-hal berikut; Aturan utama dalam muamalat adalah: Al-Ashlu fil muamalah al-ibahah illa an yadulla ad-dalilu 'ala tahrimiha. Artinya, pada dasarnya semua amalan muamalah diperbolehkan, kecuali jika ada dalil yang melarangnya. Selain itu, para ulama berpegang teguh pada standar utama muamalah, seperti aturan bebas dari riba, bebas dari gharar dan tadlis (ketidakjelasan atau ketidakpastian), tidak maysir (spekulatif), bebas dari barang haram dan tindakan fasid/kontrak batil. Aturan ini tidak boleh disalahgunakan, mengingat telah menjadi aksioma dalam fikih muamalah. (Hidayatullah, 2021)

Pada dasarnya kita bisa saja menerapkan kaidah-kaidah fikih muamalat klasik namun tidak semuanya bisa diterapkan pada jenis transaksi yang ada saat ini. Penjelasannya adalah akibat langsung dari sosio-ekonomi masyarakat yang berkembang. Al-muhafazah 'alal qadim ash-sholih wal akhzu bil jadid aslah. Yaitu memelihara warisan intelektual klasik yang masih relevan dan membiarkan terus praktik yang telah ada di zaman modern, selama tidak ada petunjuk yang mengharamkannya. Dengan prinsip tersebut, kita dapat menyimpulkan bahwa transaksi ekonomi pada masa klasik masih dapat dilaksanakan selama itu sesuai dengan kondisi, tempat dan waktu dan tidak berlawanan dengan apa yang dilarang.

Sehubungan dengan perubahan dan dampak sosial dalam masalah muamalah ini, tampaknya cocok dengan penelitian yang dikemukakan oleh Ibn Qayyim al-Jauziyyah ketika ia menetapkan sebuah kaidah yang amat relevan untuk diterapkan di zaman modern dalam mengatisipasi betrbagai jenis transaksi yang berkembang. Kaidah yang dimaksud adalah "Berubah dan berbedanya fatwa sesuai dengan perubahan tempat, zaman, kondisi sosial, niat dan adat kebiasaan”.

Ada beberapa faktor yang dapat dijadikan sebagai sumber perspektif dalam menilai suatu peristiwa, yaitu faktor tempat, faktor waktu, faktor kondisi sosial, faktor niat/tujuan, dan faktor adat. Variabel-variabel tersebut sangat persuasif dalam menentukan hukum bagi mujtahid dalam menetapkan hukum di bidang muamalah. Dalam mengelola perubahan sosial yang ditimbulkan oleh kelima komponen tersebut, yang akan dijadikan sebagai sumber perspektif dalam memutuskan hukum suatu masalah muamalah adalah pemenuhan maqashid syari'ah. Pada premis itu, maqashid syari'ah adalah proporsi sahnya suatu akad atau transaksi muamalah. (Bedoui, 2012) 


\section{Ciri-ciri Pengusaha Muslim}

Konsekuensi dari pentingnya kegiatan kewirausahaan, Islam menekankan pentingnya menciptakan dan memelihara budaya kewirausahaan dalam diri setiap Muslim. Budaya kewirausahaan muslim itu bersifat manusia relijius, berbeda dengan budaya lainnya yang tidak menjadikan pertimbangan agama sebagai landasan.

Sejalan dengan itu, seorang wirausaha muslim harus memiliki sifat-sifat fundamental yang mendorongnya untuk menjadi pribadi yang kreatif dan inovatif serta andal dalam menjalankan bisnisnya atau andal dalam bekerja di tempatnya bekerja. Sifatsifat dasar ini menggabungkan hal-hal berikut (Hunter, 2014):

\section{Terus mengagumi dan mengetahui tentang perubahan dan perbaikan}

Terus mengagumi dan mengetahui tentang perubahan dan perbaikan. Ketetapan ini ditemukan antara lain dalam gagasan aqidah. Q.S. Ar-Ra'ad: 11.

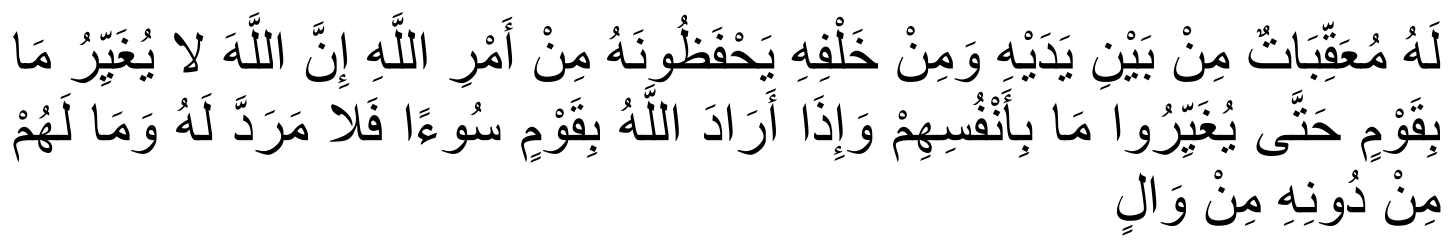

Artinya: "Bagi manusia ada malaikat-malaikat yang selalu mengikutinya bergiliran, di muka dan di belakangnya, mereka menjaganya atas perintah Allah. Sesungguhnya Allah tidak mengubah keadaan sesuatu kaum sehingga mereka mengubah keadaan yang ada pada diri mereka sendiri. Dan apabila Allah menghendaki keburukan terhadap sesuatu kaum, maka tak ada yang dapat menolaknya; dan sekali-kali tak ada pelindung bagi mereka selain Dia.”

\section{Bersifat inovatif}

Bersifat inovatif, yang membedakannya dengan orang lain. Al-Qur'an menempatkan manusia sebagai khalifah dengan tugas menumbuhkembangkan bumi, dan melakukan perubahan dan peningkatan sebagaimana Allah berfirman dalam Surah Hud 61.

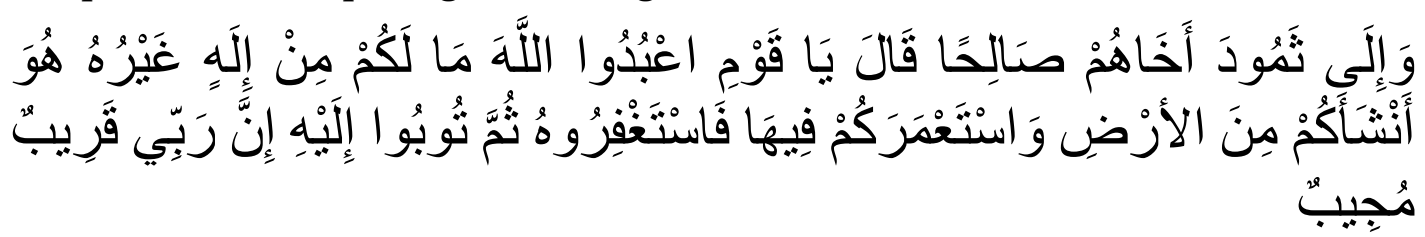

Artinya: "Dan kepada Tsamud (Kami utus) saudara mereka Saleh. Saleh berkata: "Hai kaumku, sembahlah Allah, sekali-kali tidak ada bagimu Tuhan selain Dia. Dia telah menciptakan kamu dari bumi (tanah) dan menjadikan kamu pemakmurnya, karena itu mohonlah ampunan-Nya, kemudian bertobatlah kepada-Nya. 
Sesungguhnya Tuhanku amat dekat (rahmat-Nya) lagi memperkenankan (doa hamba-Nya)."

\section{Berusahalah dengan sungguh-sungguh untuk bermanfaat bagi orang lain}

Berusahalah dengan sungguh-sungguh untuk bermanfaat bagi orang lain. Ada beberapa hadits Nabi yang menjelaskan keniscayaan seseorang untuk bermanfaat bagi orang lain. Antara lain Hadits dari Rasulullah berikut ini: "Sebaik-baik manusia adalah yang bermanfaat bagi orang lain."

\section{Selalu menyukai dan menyadari adanya ketetapan dan perubahan}

Selalu menyukai dan menyadari adanya ketetapan dan perubahan. Ketetapan itu ditemukan antara lain pada konsep akidah (Q.S. Al-Anbiya': 125). Sementara perubahan dilaksanakan pada masalah-masalah muamalah termasuk peningkatan kualitas kehidupan (Q.S. Ar-Ra'd: 11).

\section{Karakter dan kepribadian baik yang dibentuk secara terus menerus}

Karakter dan kepribadian baik yang dibentuk secara terus menerus, bukan hanya untuk sesaat atau untuk dirinya sendiri, atau orang sesamanya. Tetapi juga untuk jangka panjang, bagi generasi-generasi sesudahnya. Jadi dibutuhkan pelembagaan bagi sistem kerja para karyawan. Banyak hadits dan ayat-ayat Al-Qur'an yang memberikan tuntunan dalam hal ini diantaranya: "Bekerjalah kamu untuk dunia seolah-olah engkau hidup selama-lamanya, dan bekerjalah kamu untuk akhirat, seolah-olah kamu akan mati esok hari." (HR. Bukhari). Bisnis harus dibangun dengan berkelanjutan, bukan hanya untuk sesaat atau umtuk kepentingan individu. Melainkan untuk jangka waktu yang lebih panjang dan bagi generasi-generasi yang selanjutnya. Dan bukan hanya diusahakan berjalan baik pada masanya, tetapi juga mengalami perkembangan. Banyak hadits dan ayat yang memberikan tuntunan dalam hal ini diantaranya adalah: "Sekiranya engkau tahu bahwa engkau akan mati esok hari, maka tanamlah kurma hari ini." (HR. At-Thabrani). Adapun obyek usaha bisnisnya haruslah yang halal, sebagaimana sabda Rasulullah saw : "Barangsiapa yang dagingnya tumbuh dari yang haram, maka Allah mengharamkan jasadnya daripada surga.” (HR. At-Thabrani) (Al-Alak \& Eletter, 2010) 


\section{KESIMPULAN}

Dari pemaparan yang telah disampaikan di atas, dapat diambil beberapa kesimpulan, yaitu pengertian dasar bisnis adalah suatu pelayanan melalui jual-beli suatu barang dan jasa (the buying and selling of goods and services). Kewirausahaan merupakan kemampuan untuk berpikir dan bertindak yang konstruktif dalam mewujudkan berbagai pola produksi dan layanan secara baru. Hal ini sesuai dengan firman Allah dalam Al-Quran surat Ali Imran ayat 191, yang dalam ayat tersebut kata berpikir (وََيَتَكََُرُونَ) dapat dikaitkan dengan pola pemikiran yang kreatif terhadap kejadian di langit dan bumi serta segala potensinya. Wirausahawan sebagaimana diungkapkan, mempunyai karakteristik pemikiran yang kreatif dan inovatif serta mempunyai perilaku atau tindakan yang produktif dalam mewujudkan pembaharuan dalam pembangunan ekonomi dan bisnis, Fikih Muamalat adalah pengetahuan tentang kegiatan atau transaksi yang berdasarkan hukumhukum syariat, mengenai perilaku manusia dalam kehidupannya yang diperoleh dari dalildalil Islam secara rinci. Perkembangan bisnis kontemporer sekarang ini memang merupakan keniscayaan untuk merumuskan konsep fikih muamalah kontemporer. Walaupun konsepnya tidak relevan lagi dengan konsep bisnis kontemporer tapi prinsipprinsip dalam fikih muamalah klasik tetap dijadikan acuan dalam pembaharuan dan pembuatan produk-produk transaksi muamalah yang sesuai dengan bisnis kontemporer. Islam menekankan pentingnya perkembangan dan penegakan budaya kewirausahaan dalam kehidupan setiap muslim. Seorang wirausahawan muslim harus memiliki sifat-sifat dasar yang mendorongnya untuk menjadi pribadi yang kreatif dan andal dalam menjalankan usahanya atau menjalankan aktivitas pada perusahaan tempatnya bekerja.

\section{DAFTAR PUSTAKA}

Abdullah, R., Dja'wa, A., \& Pratiwi, E. T. (2018). Pengantar Hukum Bisnis. https://doi.org/10.31227/osf.io/txuvw

Acs, Z. (2006). How Is Entrepreneurship Good for Economic Growth? Innovations: Technology, Governance, Globalization, 1(1), 97-107. https://doi.org/10.1162/itgg.2006.1.1.97

Al-Alak, B. A. M., \& Eletter, S. (2010). Islamic Entrepreneurship: An Ongoing Driver for Social Change. Interdisciplinary Journal of Contemporary Research in Business, 1(12), 81-97. http://content.ebscohost.com/ContentServer.asp? $\mathrm{T}=\mathrm{P} \& \mathrm{P}=\mathrm{AN} \& \mathrm{~K}=59543210 \& \mathrm{~S}=\mathrm{R} \&$ $\mathrm{D}=\mathrm{bth} \&$ EbscoContent=dGJyMMvl7ESeqLQ40dvuOLCmromep7VSsKa4Ta6WxWXS \&ContentCustomer=dGJyMPGrtlGurrBRuePfgeyx44Dt6fIA\%5Cnhttp://search.ebsco host.com/login.aspx?direct $=$ true $\& d b=b t h \& A N=59543210 \&$

Anshori, I., Universitas, M. A., Surabaya, M., Anshori, I., \& Ag, M. (2009). MAQASID ALSYARI 'AH SEBAGAI LANDASAN ETIKA GLOBAL. O1(01), 14-20.

Bedoui, M. H. (2012). Shari'a. January, 1-12. 
DR. SRI SUDIARTI, M. (2013). Fikih Muamalah Kontemporer (Vol. 53, Issue 9). http://digilib.uin-suka.ac.id/25151/1/12380073_BAB-I_IV-atau-V_DAFTARPUSTAKA.pdf

Hidayatullah, M. S. (2021). URGENSI MEMPELAJARI FIKIH MUAMALAH DALAM MERESPON EKONOMI DAN KEUANGAN KONTEMPORER (Membangun Paradigma Ekonomi Syariah di Masyarakat). 5(1), 33-59.

Hunter, M. (2014). Entrepreneurship as a means to create Islamic economy. Economics, Management, and Financial Markets, 9(1), 75-100. http://ezproxy.usim.edu.my:2102/pqcentral/docview/1520014352/fulltextPDF/9491 19ADD7214BAFPQ/18?accountid=33993

Miller, R. a, \& Collier, E. W. (2010). Redefining Entrepreneurship: A Virtues and Values Perspective. Journal of Leadership, Accountability and Ethics, 8(2), 80-89. http://www.library.gatech.edu:2048/login?url=http://search.proquest.com/docview $/ 853850432$ ? accountid $=11107$

Obisi, C., \& Anyim, F. (2012). Developing the Human Capital for Entrepreneurship Challenges and Successes. International Journal of Academic Research in Business and Social Sciences, 2(3), 128-135. http://www.hrmars.com/admin/pics/676.pdf

Sabiq, S. (1983). Fikih Al-Sunna part 3.pdf. 